\title{
Alcohol and Impairments at Work and Home: How Much Matters More than How Often?
}

\author{
Randi W Aas ${ }^{1-3 *}$, Mikkel M Thørrisen ${ }^{1}$, Cecilie K Innerby ${ }^{1,3}$ and Jens Skogen ${ }^{4}$ \\ ${ }^{1}$ Faculty of Health Sciences, University of Stavanger, Stavanger, Norway \\ ${ }^{2}$ Faculty of Health Sciences, Oslo and Akershus University College, Oslo, Norway \\ ${ }^{3}$ Making Sense of Science, Stavanger, Norway \\ ${ }^{4}$ Norwegian Institute of Public Health, Bergen, Norway \\ *Corresponding author: Randi W Aas, Faculty of Health Sciences, University of Stavanger, Stavanger, Norway, E-mail: randi.aas@uis.no
}

Received date: December 26, 2017; Accepted date: January 08, 2018; Published date: January 15, 2018

Citation: Aas RW, Thørrisen MM, Innerby CK, Skogen J (2018) Alcohol and Impairments at Work and Home: How Much Matters More than How Often? J Drug Abuse Vol.4 No.1:3

\section{Introduction}

Harmful alcohol consumption constitutes a global public health issue [1]. Alcohol is a legal drug and the most common psychoactive substance in the workforce [2]. Studies conducted in developed countries have identified between 10 and $35 \%$ of employees as risky drinkers [3], characterized by having an alcohol consumption pattern that increases the risk of social, legal, medical, occupational, domestic, and economical problems [4]. Employees' alcohol consumption may influence their activity performance across domains, including the occupational and domestic spheres. Studies have found high levels of alcohol use to be associated with sickness presenteeism, i.e., reduced on-the-job productivity [5-7] as well as impaired daily activities [8-10].

Drinking frequency (how often one typically drinks during a specified time period) and drinking intensity (episodic heavy drinking or binge drinking) may have dissimilar effects on activity performance.

The aim of a recently published Norwegian study (the WIRUS screening study [1]) was to explore and compare the influence of two aspects of alcohol consumption (drinking frequency, i.e., "how often" and drinking intensity, i.e. "how much") on activity performance at work (sickness presenteeism) and outside the workplace (impaired daily activities).

Cross-sectional data from 3278 Norwegian employees across sectors and industries were collected. The sample consisted of both males and females, employees under and above age 40, and workers as well as supervisors. Drinking frequency and intensity were measured with items from the Alcohol Use Disorders Identification Test (AUDIT [4]), developed by the World Health Organization. Frequency was measured by asking participants to rate how often they had consumed alcohol during the last year. Intensity was measured by asking the respondents how often during the last year they had had binge drinking episodes, i.e., consumed six or more alcohol units on a single occasion. Sickness presenteeism and impaired daily activities were measured by asking respondents what degree of alcohol-related impairments they had experienced during the last seven days. The two activity performance items were taken from the Work Productivity and Activity Impairment questionnaire (WPAI, [11]).

Results from the WIRUS screening study showed that drinking intensity displayed significant associations with both sickness presenteeism and impaired daily activities, which, according to the authors, may be explained by binge drinking episodes being associated with short-term consequences (e.g. hangover symptoms, decreased attention and concentration, as well as other temporary physical, cognitive and psychological disturbances) [12,13]. Drinking frequency did display a significant association with impaired daily activities, but to a lesser degree than drinking intensity. The authors emphasize that frequent drinking over time is a risk factor for long-term health complications. However, high-frequency drinking would not necessarily produce short-term impairments comparable to binge drinking episodes.

The study also found that drinking intensity displayed a stronger association with impaired daily activities than with sickness presenteeism. Stated differently: Binge drinking showed a stronger influence on activity impairment outside the workplace than at work. This may, according to the authors, be explained by binge drinking episodes being most prevalent in weekends and holidays and that fear of formal and informal sanctions may motivate the individual to mobilize energy in order to override alcohol-related impairments at the workplace.

The study collected cross-sectional information on alcohol consumption and experienced activity impairments. Hence, it is not possible to draw causal inferences about the relationships between drinking patterns and activity impairments. Another limitation is that alcohol consumption was measured in a time frame of 12 months while activity impairments were rated based on a 7 days interval. Implications for future research include the need for studies investigating the temporal association between alcohol consumption and activity performance by means of longitudinal designs.

However, the WIRUS screening study implies that there are meaningful and important relationships between alcohol consumption and activity performance both at work and outside 
the workplace. Furthermore, results from the study imply that interventions aiming to prevent alcohol-related problems among employees should have a particular emphasis on binge drinking behavior.

\section{References}

1. Aas RW, Haveraaen L, Sagvaag, H, Thørrisen MM (2017) The influence of alcohol consumption on sickness presenteeism and impaired daily activities. The WIRUS screening study. PLoS One 12: e0186503.

2. Frone MR (2004) Alcohol, drugs and workplace safety outcomes: A view from a general model of employee substance use and productivity. In: Barling J, Frone MR, eds. The psychology of workplace safety. Washington, DC. American Psychological Association, pp: 127-156.

3. Nesvåg S, Lie T (2004) Rusmiddelbruk blant ansatte i norsk privat arbeidsliv [Drug use among employees in Norwegian private sector]. Nordisk Alkohol- og Narkotikatidsskrift 21: 91-109.

4. Babor TF, Higgins-Biddle JC, Saunders JB, Monteiro MG (2001) AUDIT: The alcohol use disorders identification test. Guidelines for use in primary care. 2nd ed. Geneva, Switzerland: World Health Organization.

5. Kirkham HS, Clark BL, Bolas CA, Lewis GH, Jackson AS, et al. (2015) Which modifiable health risks are associated with changes in productivity costs? Popul Health Manag 18: 30.
6. Mangione TW, Howland J, Amick B, Cote J, Lee M, Bell N, et al. (1999) Employee drinking practices and work performance. J Stud Alcohol 60: 261-270.

7. Riedel EJ, Grossmeier RJ, Haglund-Howieson EL, Buraglio EC, Anderson ED, et al. (2009) Use of a normal impairment factor in quantifying avoidable productivity loss because of poor health. J Occup Environ Med 5: 283-295.

8. McKechnie J, Hill E (2009) Alcoholism in older women religious. Substance Abuse 30: 107-117.

9. Saarni SI, Suvisaari J, Sintonen H, Pirkola $S$, Koskinen $S$, et al (2007). Impact of psychiatric disorders on health-related quality of life: General population survey. Br J Psychiatry 190: 326-332.

10. Rodriguez LM, Dibello AM, Neighbors C (2013) Perceptions of partner drinking problems, regulation strategies and relationship outcomes. Addict Behav 38: 2949-2957.

11. Reilly MC, Zbrozek AS, Dukes EM (1993) The validity and reproducibility of a work productivity and activity impairment instrument. Pharmacoeconomics 4: 353-365.

12. Blum TC, Roman PM, Martin JK (1993) Alcohol-consumption and work performance. J Stud Alcohol 54: 61-70.

13. Verster JC (2008) The alcohol hangover - A puzzling phenomenon. Alcohol Alcohol 43: 124-126. 